\title{
A educação a distância no processo de formação continuada da administração pública: as contribuições da Revista do Serviço Público
}

Débora Duran

Exército Brasileiro

No ano em que a Enap comemora 30 anos, nada mais oportuno que apresentar as contribuições da Revista do Serviço Público (RSP) para a discussão sobre a profissionalização dos serviços públicos. Nesse sentido, o objetivo deste artigo é refletir sobre os modos pelos quais a educação a distância, enquanto estratégia de formação continuada capaz de propiciar novas dinâmicas de ensino e aprendizagem, tem sido tematizada e problematizada nos contornos do periódico nacional mais longevo na área de administração pública. O conjunto dos 575 textos publicados na RSP, desde 1989 até os dias atuais, contempla artigos, ensaios, entrevistas, reportagens e resenhas que expressam, direta ou indiretamente, múltiplas perspectivas a respeito dos desafios da formação continuada. Entre eles, a educação a distância (EAD) revela-se como tendência irreversível no contexto da denominada sociedade da informação, uma vez que as potencialidades das tecnologias digitais da informação e comunicação (TDIC) apontam para o rompimento das barreiras espaço-temporais, bem como para a emergência do paradigma da interatividade, que impõe a superação do modelo tradicional de formação profissional.

Palavras-chave: educação a distância, educação continuada, escola de governo, servidor público, administração pública

[Artigo recebido em 30 de junho de 2016. Aprovado em 21 de fevereiro de 2017.] 
La educación a distancia en el proceso de formación continuada de la administración pública: las contribuciones de la Revista del Servicio Público

En el año en que la Enap celebra sus 30 años, no hay nada más oportuno que presentar las contribuciones de la Revista del Servicio Público (RSP) para las discusiones sobre la profesionalización de los servicios públicos. En ese sentido, el objetivo de este artículo es reflexionar acerca de los modos con los cuales la cuestión de la formación continuada, subrayándose la educación a distancia, ha sido debatida y planteada en los límites del periódico nacional de mayor longevidad en el área de la administración pública. El conjunto de 575 textos publicados en la RSP contempla, desde el año 1989 y hasta los días de hoy, artículos, ensayos, entrevistas, reportajes y reseñas que expresan, directa o indirectamente, múltiples perspectivas respeto al referido tema. Entre los cuales, educación a distancia se revela como una tendencia irreversible en el contexto de la denominada sociedad de la información, ya que el potencial de las tecnologías digitales de la información y comunicación (TDIC) apuntan a la ruptura de los límites espacio-temporales, así como la aparición de paradigma de la interactividad requiere la superación del modelo tradicional de formación profesional.

Palabras clave: educación a distancia, educación continua, escuela de gobierno, servidor público, administración pública

Distance education in the process of continuing education in public administration: the contributions of the Public Service Review

In the year Enap celebrates its 30th anniversary, nothing sounds more appropriate than presenting the Public Service Review (PSR) contributions concerning the professionalization of the public administration services. In this regard, the aim of this paper is to present a reflection on the ways in which the continuing education has been approached and discussed in the longest-living national journal in the area of public administration, regarding distance education. The set of 575 texts issued by PSR since 1989 until the current days includes articles, essays, interviews, reports and reviews that express, directly or indirectly, multiple perspectives relating to the subject. Among which distance education reveals itself as an irreversible trend in the context of the so-called information society, since the potentialities of the digital information and communication technologies (TDIC) point to the breakdown of the space-time barriers, as well as to the emergence of the paradigm of interactivity that imposes the overcoming of the traditional model of professional training.

Keywords: distance education, continuing education, government school, public server, public administration 


\section{Introdução}

Lançada em novembro de 1937, a Revista do Serviço Público (RSP) destaca-se por ser, no Brasil, a mais longeva do gênero. Durante esse período, os conteúdos veiculados em quase oito décadas de existência revelam-se como importante expressão intelectual de autores dedicados à reflexão sobre a administração pública nacional. Nesse sentido, é lícito afirmar que o periódico apresenta valor inconteste na estruturação da área, bem como na gênese e desenvolvimento do pensamento administrativo nacional. Entre os diversos temas nela abordados, interessa-nos, no teor deste texto, focalizar o da formação continuada dos servidores públicos, dada a sua relevância social. Ademais, essa temática reveste-se de especial importância por ter sido contemplada na pauta desta edição comemorativa como um dos eixos norteadores para as reflexões dos autores.

O ano de 2016 constitui-se num marco de celebração da profissionalização da função pública no Brasil. Comemoramos 30 anos de criação da Escola Nacional de Administração Pública (Enap) e, em sua esteira, a implementação das escolas de governo e das ações de formação continuada em administração pública. Em consonância com tais iniciativas, merece especial destaque o papel desempenhado pela Revista do Serviço Público enquanto periódico de caráter oficial e acadêmico, tanto para a formação dos servidores como para a consolidação da área.

Destarte, com base na classificação dos títulos constantes nos sumários dos números publicados entre os anos de 1989 e 2016 ${ }^{1}$, tencionamos apresentar as contribuições atinentes à formação continuada, devidamente fundamentadas em diferentes aportes teórico-metodológicos. Pretendemos, assim, refletir sobre os modos pelos quais a questão da educação dos servidores tem sido tematizada e problematizada nos contornos de um periódico que se tornou referência na área de administração pública. Adicionalmente, é também nossa intenção apontar para as perspectivas de inovação nas práticas de capacitação, com especial destaque para os novos horizontes formativos relacionados à educação a distância.

\section{Revista do Serviço Público: das origens aos dias atuais}

O histórico e as tendências da RSP foram amplamente discutidos por Keinert e Vaz (1994a, 1994b) em dois artigos complementares que apresentam os resultados de uma pesquisa quanti-qualitativa sobre a produção brasileira em administração pública. Com base nessas referências, pretendemos apresentar algumas informações necessárias à compreensão da trajetória do periódico em pauta.

\footnotetext{
${ }^{1}$ Números disponíveis para consulta no site da revista.
} 
O lançamento da RSP data de novembro de 1937, sob responsabilidade do Conselho Federal do Serviço Público Civil (CFSPC). No ano seguinte, foi direcionada para o Departamento Administrativo do Serviço Público (Dasp), por ocasião de sua criação, sendo posteriormente transferida para a Fundação Centro de Formação do Servidor Público (Funcep), no período entre 1981 e 1989. A partir de 1994, a publicação da revista ficou a cargo da Enap.

De acordo com os autores, há duas tendências básicas que norteiam as publicações: a oficial e a científica; ora conflitantes, ora complementares. Com base nos dados que foram coletados no âmbito da pesquisa supracitada, podemos apresentar uma síntese da periodização que é resultado da análise minuciosa realizada pelos pesquisadores (Quadro 1).

Quadro 1 - RSP - periodização

\begin{tabular}{|c|c|c|c|}
\hline Período & Contexto & Público-alvo & Enfoque \\
\hline $\begin{array}{l}\text { Estruturação } \\
\text { (1937-1945) }\end{array}$ & $\begin{array}{l}\text { Bases do Estado } \\
\text { administrativo } \\
\text { e busca pela } \\
\text { profissionalização } \\
\text { do funcionalismo }\end{array}$ & $\begin{array}{l}\text { Público } \\
\text { interno }\end{array}$ & $\begin{array}{l}\text { Administrativo } \\
\text { Surgimento } \\
\text { da Ciência da } \\
\text { Administração } \\
\text { como campo de } \\
\text { conhecimento }\end{array}$ \\
\hline $\begin{array}{l}\text { Consolidação } \\
\text { (1946-1964) }\end{array}$ & $\begin{array}{l}\text { Fim do Estado- } \\
\text { Novo, cenário } \\
\text { nacional marcado } \\
\text { pelos projetos } \\
\text { de cooperação } \\
\text { internacional } \\
\text { e esboço das } \\
\text { primeiras propostas } \\
\text { de descentralização }\end{array}$ & $\begin{array}{l}\text { Estudiosos e } \\
\text { profissionais } \\
\text { de } \\
\text { administração }\end{array}$ & $\begin{array}{l}\text { Científico } \\
\text { Revista enquanto } \\
\text { espaço catalisador } \\
\text { do campo de } \\
\text { conhecimento em } \\
\text { administração }\end{array}$ \\
\hline $\begin{array}{l}\text { Ruptura } \\
\text { (1965-1979) }\end{array}$ & $\begin{array}{l}\text { Governos militares } \\
\text { Reforma } \\
\text { Administrativa, } \\
\text { planejamento como } \\
\text { princípio dominante }\end{array}$ & Heterogêneo & $\begin{array}{l}\text { Oficial } \\
\text { Artigos produzidos } \\
\text { por autoridades e } \\
\text { ocupantes de altos } \\
\text { cargos }\end{array}$ \\
\hline $\begin{array}{l}\text { Redemocratização } \\
\text { (1980-1989) }\end{array}$ & $\begin{array}{l}\text { Crise internacional, } \\
\text { transição para } \\
\text { o sistema } \\
\text { democrático }\end{array}$ & $\begin{array}{l}\text { Público } \\
\text { interno* }\end{array}$ & $\begin{array}{l}\text { Divulgação e } \\
\text { informação } \\
\text { Posteriormente, } \\
\text { proposta } \\
\text { acadêmica }\end{array}$ \\
\hline
\end{tabular}

Fonte: Elaboração própria com base nos artigos de referência.

* Inclui os denominados "executivos de Estado" ou administradores públicos profissionais, além de um corpo técnico que atua nas administrações direta e indireta. 
Em relação à classificação dos 3898 artigos publicados nesse período, foram adotados os termos focus e locus como categorias de análise ${ }^{2}$. O focus diz respeito à perspectiva teórica assumida pelos autores que produziram os textos, ou seja, aos conceitos utilizados para realizar a seleção e interpretação dos fatos e que permitem a definição dos posicionamentos a respeito das questões abordadas. Nas palavras dos referidos pesquisadores, o locus, por sua vez, diz respeito aos fenômenos empíricos que constituem o objeto da análise, o que define o território que deve ser explorado.

Para a primeira categoria, foram identificados os seguintes enfoques: Ciência Política, Ciência Jurídica, Ciência Administrativa, Ciência Econômica, Epistemologia e uma categoria genérica, denominada outros. Para a segunda, foram computados 39 itens, devidamente distribuídos em quatro grupos distintos, a saber: estruturação da administração do Estado, organização econômica, políticas setoriais e ensino e pesquisa. Enquanto a primeira diz respeito ao quê sobre o campo (specialized what), a segunda está atrelada ao local institucional (institucional where).

Neste trabalho, mesmo não tendo a mesma pretensão metodológica, organizamos os conteúdos publicados na RSP desde 1989 até os dias atuais, de acordo com os sumários constantes nos 86 números analisados. Essa proposta de sistematização ${ }^{3}$, ainda que incipiente, constitui-se num ponto de partida para que possamos compreender a trajetória do periódico nas últimas três décadas, bem como suas contribuições. Os sumários contemplam 395 artigos, 1 bibliografia, 3 documentos, 62 ensaios, 15 editoriais, 4 entrevistas, 4 textos sobre ensino e pesquisa, 1 índice remissivo, 4 palestras, 13 resenhas, 21 reportagens e 41 artigos revisitados.

De 1989 até os dias atuais, podemos considerar diversos fatores que tiveram influência direta ou indireta sobre o contexto de publicação da RSP. Os diversos mandatos presidenciais foram marcados por intensas transformações nos planos internacional e nacional, destacando-se o aprofundamento do processo de globalização e a ascensão das tecnologias digitais de informação e comunicação. Vale destacar a criação (1988) e a extinção (1989) do Ministério da Administração Federal e Reforma do Estado (Mare), a Reforma do Estado, a partir dos anos 1990, bem como a publicação do Decreto no 5.707, de 2006, que institui a política e as diretrizes para o desenvolvimento de pessoal da administração pública federal direta, autárquica e fundacional com foco no conceito de competência. Em relação ao enfoque, a revista permanece com um cariz acadêmico, apesar da publicação de textos institucionais; e, quanto ao público-alvo, contempla os públicos interno

\footnotetext{
2 Essas categorias estão fundamentadas em Golembiewski (1977).

${ }^{3}$ Apêndice - Títulos publicados na RSP: 1989-2016.
} 
e externo por meio de reflexões que articulam teorias e práticas envolvidas na dinâmica laboral da administração pública.

No conjunto do material analisado ${ }^{4}$, merecem destaque alguns aspectos pontuais. Nas últimas três décadas, a RSP publicou 575 textos, destacando-se 457 que incluem artigos e ensaios. Entre os anos de 1990 e 1993, a publicação foi suspensa; e o ano de sua retomada, 1994, foi o que contou com o maior número de textos. Digno de nota é o fato de que a edição com maior quantidade de conteúdo (volume 45, n. 3), com o total de 30 textos, também foi publicada nesse ano.

Os editoriais foram publicados nos anos de 1994 e 1995 e, depois, somente a partir de 2014. Os documentos oficiais aparecem apenas no primeiro ano e mais uma única vez, em 1996, ao passo que as resenhas constam em poucos números, somente nos quatro primeiros anos do período analisado. A categoria ensino e pesquisa, relacionada aos textos institucionais de caráter oficial sobre iniciativas e projetos diversos, esteve presente nos anos de 1994 e 1995. As palestras e entrevistas foram publicadas de modo aleatório, sem uma sequência ou frequência específica. As reportagens podem ser encontradas entre os anos de 2005 e 2012, e, ainda que não tenham sido uma constante em todas as edições, tiveram continuidade ao longo de oito anos. A categoria RSP Revisitada diz respeito aos artigos publicados em edições anteriores que, em função de sua relevância, foram selecionados para nova publicação.

De 2005 aos dias atuais, com exceção de cinco edições, os artigos revisitados foram (re)publicados regularmente, resgatando-se, assim, acervos de importância e de difícil acesso, em função até do tempo de existência prolongado da RSP.

\section{A formação continuada em foco}

No conjunto das temáticas abordadas ao longo da trajetória histórica da RSP, a formação continuada dos servidores públicos merece especial destaque. Em tempos de revolução informacional, o investimento na formação continuada revela-se como condição fundamental ao atendimento das novas demandas sociais, econômicas e culturais desencadeadas pela articulação entre o processo de globalização e a ascensão das tecnologias digitais de informação e comunicação. Segundo Lojkine (1999), estamos diante de uma organização social sui generis, na qual o processamento da informação, bem como sua disseminação e desdobramentos colocam o conhecimento na centralidade do sistema produtivo.

\footnotetext{
${ }^{4}$ O conjunto de textos selecionados para análise contempla apenas o período entre 1989 e 2016, já que os volumes dos anos anteriores não estão disponíveis online. Apesar da limitação, os dados referentes ao último vintênio constituem um corpus consistente para a reflexão sobre a temática em pauta.
} 
Nesse sentido, diversos autores, baseados em perspectivas teóricas distintas e por vezes divergentes, anunciam a chegada do que se convencionou chamar de sociedade pós-industrial, sociedade pós-moderna, sociedade da informação e sociedade em rede, entre outras terminologias afins (KUMAR, 2006; MATTELART, 2002; CASTELLS, 1999).

A formação continuada pode ser compreendida como um conjunto de iniciativas e práticas educativas concebidas, planejadas e implementadas com o objetivo de propiciar oportunidades de desenvolvimento profissional. Diante do ritmo acelerado das transformações no mundo do trabalho, já não é mais razoável sustentar a ideia de formatura, ao menos em termos absolutos. O mote do profissional formado deu lugar ao anúncio do profissional formando-se, razão pela qual a formação continuada impõe-se como prática desejável e necessária nos setores público e privado.

No setor privado, funcionários de todos os níveis estão envolvidos em processos de aprendizagem contínua com foco na melhoria de sua performance profissional. Em decorrência da competitividade e da inovatividade típicas da economia do conhecimento, que exige qualificações e competências mais amplas, a iniciativa privada tem aumentado seu compromisso e, consequentemente, o investimento na formação continuada de suas equipes de trabalho (MEISTER, 1999).

No setor público, a formação continuada constitui-se num elemento central para a melhoria da qualidade dos serviços prestados. Imbernón (2010a, 2010b), ao tratar da formação continuada de professores, apresenta uma discussão plenamente compatível com os desafios do setor público em geral. A seu ver, a formação continuada pode ser considerada como fulcro para o desenvolvimento pessoal, profissional e institucional, uma vez que concorre para a transformação da prática. Deve, então, contribuir para os processos de mudança e, ademais, para a reflexão sobre as consequências decorrentes de tais processos. Segundo o autor, o conhecimento profissional depende da aquisição de conhecimentos teóricos, do desenvolvimento de competências atreladas ao processamento da informação, à análise e à reflexão ocorridas na e sobre a ação educativa e, inclusive, da avaliação e da reformulação de projetos.

Dada a sua relevância, a formação continuada tem recebido especial destaque no conjunto dos diversos volumes da RSP. Essa temática foi, ao longo dos últimos vinte anos, contemplada em inúmeros textos da revista que atestam a importância crucial de tal discussão para o desenvolvimento do setor. Na Tabela 1, apresentamos os dados relacionados a todas as edições nas quais o tema foi direta ou indiretamente abordado nas diversas categorias constantes nos sumários. 
Tabela 1 - A formação continuada na RSP

\begin{tabular}{|c|c|c|c|c|c|c|c|c|}
\hline Ano & Volumes & Artigo & Ensaio & $\begin{array}{l}\text { Ensino e } \\
\text { Pesquisa }\end{array}$ & Reportagem & Palestra & $\begin{array}{l}\text { RSP } \\
\text { revisitada }\end{array}$ & TOTAL \\
\hline \multirow{2}{*}{1994} & v. 45 n. 1 & - & - & 1 & - & - & - & 1 \\
\hline & v. 45 n. 2 & - & 3 & 1 & - & - & - & 5 \\
\hline 1995 & v. 46 n.1 & - & 1 & - & - & - & - & 1 \\
\hline \multirow{2}{*}{1999} & v. 50 n. 2 & 1 & - & - & - & - & - & 1 \\
\hline & v. 50 n. 4 & 1 & - & - & - & - & - & 1 \\
\hline 2000 & v. 51 n. 2 & 1 & - & - & - & - & - & 1 \\
\hline 2002 & v. 53 n.1 & 1 & - & - & - & - & - & 1 \\
\hline 2003 & v. 54 n. 2 & 1 & - & - & - & - & - & 1 \\
\hline \multirow{2}{*}{2005} & v. 56 n. 2 & - & - & - & - & 1 & - & 1 \\
\hline & v. 56 n. 3 & - & 1 & - & - & - & - & 1 \\
\hline 2007 & v. 58 n. 3 & 1 & - & - & 1 & - & 1 & 3 \\
\hline 2009 & v. 60 n.2 & 1 & - & - & - & - & - & 1 \\
\hline \multirow{2}{*}{2010} & v. $61 \mathrm{n} .3$ & 1 & - & - & - & - & - & 1 \\
\hline & v. 61 n. 4 & - & - & - & - & - & 1 & 1 \\
\hline \multirow[t]{2}{*}{2011} & v. 62 n. 3 & 1 & - & - & - & - & - & 1 \\
\hline & v. 62 n. 4 & - & - & - & - & - & 1 & 1 \\
\hline 2012 & v. 63 n. 2 & - & - & - & 1 & - & 1 & 2 \\
\hline \multirow{2}{*}{2013} & v. 64 n.1 & 1 & - & - & - & - & - & 1 \\
\hline & v. 64 n.2 & 1 & - & - & - & - & - & 1 \\
\hline 2014 & v. 65 n. 3 & 1 & - & - & - & - & - & 1 \\
\hline Total & 22 & 12 & 5 & 2 & 2 & 1 & 4 & 27 \\
\hline
\end{tabular}

Fonte: Elaboração própria com base na análise dos sumários da RSP (1989-2016).

No total, foram apresentados 27 textos relacionados à formação continuada, o que corresponde, em termos percentuais, a aproximadamente $4 \%$ do total dos títulos publicados. Entre eles, 12 artigos, 5 ensaios, 2 textos na categoria Ensino e Pesquisa, 2 reportagens, 1 palestra e mais 4 artigos revisitados.

Após apresentarmos os dados quantitativos relacionados ao período que compreende o ano da retomada da publicação até os dias atuais, faremos agora algumas considerações sobre os conteúdos veiculados no conjunto das edições da RSP. Os títulos que contemplam a temática da formação continuada podem ser classificados com base em diferentes critérios. Como uma das vias possíveis, entendemos que foram três os focos escolhidos pelos autores para anunciar suas reflexões, a saber: profissionalização, escolas de governo e educação a distância. A profissionalização, em suas múltiplas dimensões, contou com 10 reflexões, sendo 4 artigos, 3 ensaios e 3 artigos revisitados. As escolas de governo, enquanto assunto de especial interesse, foram contempladas em 10 textos, sendo 2 artigos, 2 ensaios, 2 textos sobre estudos e pesquisas, 2 reportagens, 1 palestra e 1 artigo revisitado. No teor das edições, a primeira discussão sobre educação a distância foi apresentada em 2007 e, até o ano corrente, conta com 7 textos, sendo 6 artigos e 1 reportagem. 


\section{Profissionalização}

A profissionalização, como uma temática geral, foi contemplada nas reflexões de diversos autores. No conjunto dos textos, alguns assuntos específicos foram enfocados, tais como: desenvolvimento, novos espaços de formação, liderança, carreiras e mapeamento da oferta de capacitação, entre outros. Dada a relevância e amplitude da temática, os diferentes aspectos tomados como objeto de reflexão revelam-se como expressão da complexidade que a envolve.

Ricupero (1994) destaca, em seu ensaio, que a profissionalização do servidor público é condição sine qua non ao desenvolvimento, já que a ausência ou deficiência no aparato burocrático pode comprometer a concretização de projetos de interesse público. A seu ver, a profissionalização dos servidores é uma estrada de duas vias, uma vez que, para que se possa cobrar um bom desempenho profissional, faz-se necessário, primeiramente, oferecer as condições necessárias para sua efetivação.

Em relação ao conceito de formação, o ensaio de Dowbor (1994) enfatiza que a educação está diante de uma nova dinâmica e, portanto, diante de novos desafios. Em face das novas configurações do mundo globalizado, a mudança não diz respeito a uma situação, mas a um processo contínuo e irreversível. Com o avanço tecnológico, a ideia de aprendizagem não pode mais ser confundida com a de "estoque", uma vez que aponta, cada vez mais, para a perspectiva de navegação. No mesmo sentido, ocorre ainda a transformação daquilo que o autor denomina de "cronologia do conhecimento", ou seja, a sequência convencional estudo-trabalhoaposentadoria dá lugar à de formação permanente, como um continuum que perpassa toda a trajetória profissional dos trabalhadores.

De toda forma, é nossa visão de que a dimensão de investimento no homem tem sido insuficientemente realçada numa visão frequentemente estéril da modernização, que prioriza o prédio e a máquina. Uma visão ao mesmo tempo moderna e humanista poderá constatar que o mundo educacional está adormecido ao lado de um gigantesco manancial de possibilidades subutilizadas, e que tem de começar a trabalhar por espaços mais amplos e renovados, com tecnologias e soluções institucionais novas (DowBoR, 1994, p.168).

A diversificação dos espaços de conhecimento revela-se na ampliação e na interconexão entre práticas de ensino e de aprendizagem que ultrapassam os limites da educação formal propriamente dita. As diferentes mídias, os espaços de conhecimento comunitário, os cursos técnicos especializados, a organização do ambiente científico familiar e as instituições de ensino e pesquisa se fundem, com a emergência das tecnologias da informação e comunicação, num espaço sui generis que impõe a superação do modelo convencional "lecionador" por um projeto educativo "mobilizador". A rigor, tal perspectiva não se limita apenas à escola, em 
sentido restrito, já que diz respeito à educação em sentido geral, levando-se em consideração a formação inicial e continuada.

O artigo de Newcomer (1999) aborda a preparação dos gerentes públicos para o século 21, com foco na discussão da obsolescência das formas tradicionais na condução dos negócios. A autora é enfática ao afirmar que, para aconselhar políticos e atender aos seus questionamentos, os gerentes públicos necessitam de treinamento específico, de tal maneira que os responsáveis por sua formação devem promover oportunidades de aprendizagem propícias à inovação a fim de que os gerentes sejam capazes de enfrentar os desafios no ambiente da administração pública. Os gastos com essa formação devem ser considerados como investimentos prioritários, uma vez que a melhoria do desempenho do governo depende do rompimento em relação a ideias fixas e padrões cristalizados.

O treinamento eficaz contempla basicamente quatro aspectos, a saber: os gerentes devem entender que o aprendizado não se limita a momentos, uma vez que deve durar a vida inteira; os formadores de gerentes devem promover oportunidades para o desenvolvimento de habilidades, valendo-se da utilização das tecnologias de informação e comunicação; os gerentes devem ser "bilíngues" (dominar as línguas dos setores público e privado) e, ademais, precisam ser envolvidos em atividades que exijam sua atuação como instrutores de seus pares.

Bacon (1999) discute a questão da capacitação, mas com especial destaque para a importância do desenvolvimento da liderança. Segundo o autor, a liderança dinâmica é fundamental no processo de transformação das organizações, razão pela qual o setor privado demonstra que está atento à importância da direção. Tal preocupação revela-se nos altos salários dos executivos, nos investimentos em programas de valorização de suas competências e, inclusive, na ampla variedade de títulos técnicos publicados a respeito do tema.

O artigo apresenta algumas linhas de ação que podem nortear as organizações do setor público no intuito de formar, no grupo dos servidores, futuros líderes. Diante das competências necessárias aos líderes do futuro e das próprias limitações do serviço público, o autor apresenta, como sugestão, seis etapas:

1) compromisso do mais alto escalão da organização com o desenvolvimento de futuros líderes;

2) desenvolvimento das competências de liderança por meio da diversificação de tarefas;

3) desenvolvimento da autoconsciência das competências de liderança, graças a um melhor feedback e experiências formadoras;

4) incentivo e monitoramento do uso da ampliação de tarefas, com vistas ao desenvolvimento dos recursos humanos;

5) consolidação do senso do serviço público; 
6) realização periódica de auditorias de liderança (leadership audits) dentro da organização (BACON, 1999, p. 83).

Coincidentemente, anos depois, o próximo artigo sobre profissionalização também aborda a questão de liderança. Smith (2003) concorda com a necessidade de inovação, mas destaca que o primeiro desafio é convencer as pessoas da importância de participarem dos programas que são oferecidos.

O primeiro desafio é conseguir que as pessoas venham, participem dos programas oferecidos. Isso se choca com a infeliz realidade de que o urgente sempre parece deixar de lado o importante. Muitos (a maioria?) dos gerentes ou não acreditam que precisam da capacitação dos eventos para os quais não têm tempo, ou têm dúvidas sobre a relevância e pertinência dos cursos de capacitação oferecidos (SMITH, 2003, p.107).

Para o autor, os cursos devem ser de curta duração e altamente focados. Os princípios andragógicos ${ }^{5}$ devem privilegiar a experiência dos cursistas, o trabalho em grupo, diferentes metodologias de ensino e desenho didático flexível. Em suas próprias palavras, a capacitação em liderança requer "a ligação viva com o mundo da política e da implementação de forma a atrair bons profissionais ao aprendizado e a encurtar o tempo de reação entre o aprendizado e sua aplicação na máquina do Estado" (SMITH, 2003, p.108).

Rosa (2005) apresenta uma reflexão de cunho teórico e discute a questão da cidadania em tempos de civilização tecnológica. No teor do texto, discute a necessária mudança nos quadros conceituais relacionados à formação, à educação e ao conhecimento, já que alguns os produzem e outros os repetem ativamente (professores) ou passivamente (alunos).

No que respeita ao pedagógico propriamente dito, o mínimo que se pode dizer é que deixou de ser "propriamente dito". O pedagógico só é concebível hoje em dia como científico-pedagógico, entendido igualmente o "científico" no contexto de sentido que se deu ao "tecnológico". Aprender não é, hoje, repetir e reiterar os conhecimentos produzidos por via científica e mediatizados por via técnica. Aprender é re-produzir, re-criar, saber a partir daquilo que faz a própria existência e dos próprios actos da vida. Todo o esforço da interdisciplinaridade é ainda ilusório e inglório. O saber é transdisciplinar, implantado numa realidade "tópica" que se encontra aquém, para além e atravessando as disciplinas, todas as disciplinas (ROSA, 2005, p. 328).

\footnotetext{
${ }^{5}$ Andragogia (andros = adulto + agogus = guiar, conduzir, educar para a formação de adultos): conjunto de teorias e práticas educacionais que considera a maturidade biológica dos aprendizes, juntamente com seu rol de experiências acumuladas, psicológicas, afetivas, profissionais e culturais, que implicam maior grau de autonomia nas decisões sobre como estudar (FILATRO; MotA, 2013, p.109).
} 
O artigo de Ferrarezi e Tomacheski (2010) constitui-se num relato sobre o projeto Mapeamento da Oferta de Capacitação nas Escolas de Governo. Essa iniciativa foi possível graças ao trabalho conjunto das escolas participantes da Rede Nacional de Escolas de Governo, criada em 2003, em parceria com a Enap. Desde sua implementação, em 2008 , o projeto de mapeamento objetiva coletar dados da oferta existente de eventos de formação e capacitação nas escolas de governo integrantes da rede. O produto dessa iniciativa diz respeito a um instrumento de informações gerenciais, denominado Sistema Mapa, que reúne elementos diversos sobre a oferta de capacitação no serviço público. O compartilhamento tem como finalidade a classificação e a comparação de conteúdos, bem como a identificação de tendências de capacitação, temas emergentes, gaps e potenciais para o desenvolvimento de competências específicas.

De acordo com os autores supracitados, a grande maioria dos servidores públicos brasileiros está ligada aos governos municipais ou estaduais, assim como a maior parte dos servidores públicos federais está lotada fora do centro administrativo da capital federal, em Brasília. Sendo assim, a concepção de planos de capacitação em larga escala deve levar em consideração a questão geográfica e ter informações suficientes para realizar o planejamento das ações voltadas à formação continuada. Ademais, a articulação entre as três esferas federativas é uma exigência no contexto dos processos de democratização e descentralização que sustentam a implementação das políticas públicas.

Os três artigos revisitados (SOIFER, 2007; SIQUEIRA, 2010; MAGALHÃES, 2011) versam sobre revolução educacional, seleção e treinamento dos servidores do Estado. O primeiro, de autoria de Soifer (2007), destaca os problemas de ordem quantitativa e qualitativa da educação brasileira e aponta para uma necessária revolução com o apoio da então denominada tecnologia educacional. O artigo, publicado originalmente em 1971, já anunciava um processo progressivo que viria a culminar, em nossos dias, na educação online. O segundo, escrito por Siqueira (2010), destaca a importância de processos de recrutamento que incluam programas de treinamento prévio - pre-entry training - e, já em 1950, destacava a importância da preparação de servidores para o exercício profissional. O terceiro e último artigo, de autoria de Magalhães (2011), publicado pela primeira vez em 1942, revela a preocupação com a qualificação do servidor público para além da aprendizagem continuada, destacando a importância de bons cursos de formação inicial, algo incomum à época.

\section{Escolas de governo}

A criação de uma escola de governo e sua função no Estado foi tema do artigo revisitado de Berquió (2012), publicado originalmente em agosto de 1938. O texto 
aborda a proposta de lei, de 1936, para a criação da Escola Nacional de Administração, na França, que só viria a se tornar realidade em 1945, com a promulgação da nova constituição e a inauguração da École Nationale d'Aministration (ENA). A seu ver, uma escola de administração deveria contribuir para o aperfeiçoamento de funcionários especializados e para a renovação constante do grupo de dirigentes, e conclui que "o Brasil precisa igualmente de um estabelecimento de ensino desse gênero: pois o nosso Serviço Civil ainda carece, infelizmente, de um autêntico escol de grandes funcionários" (BERQUió, 2012, p. 240).

Os ensaios sobre as escolas de governo, uma vez instituídas no Brasil, foram inaugurados por Gaetani (1994). O autor destaca a importância de uma ação mais efetiva, por parte do governo, no processo de formação de dirigentes das burocracias públicas e discute a complexidade da questão e aspectos importantes sobre a capacitação, a remuneração e as carreiras. Santos e Brito (1995) abordam os novos desafios do mundo globalizado e suas implicações no processo de profissionalização dos servidores públicos. Após a análise de diversas experiências internacionais, os autores concluem que, no caso brasileiro, a flexibilidade deve ser a pedra angular na escolha dos modelos das escolas e na definição dos perfis dos profissionais para os altos escalões da burocracia e, por consequência, dos demais níveis. Com base na ideia do analista simbólico proposta por Robert Reich (1995) no clássico $O$ trabalho das nações, a sugestão é a de que os profissionais para os níveis superiores da burocracia possam combinar, a depender de cada caso, os perfis generalista, especialista e híbrido (generalista com especialização). Em relação às instituições formadoras, os autores sustentam a necessidade de consolidação de uma rede nacional capitaneada pela Enap.

Os dois artigos que tratam das escolas de governo foram escritos pela então presidente da Enap, Regina Silvia Pacheco. O primeiro texto, publicado no ano 2000, apresenta uma análise sobre as escolas de governo latino-americanas, sua origem, evolução e perspectivas. Com base na história institucional da Enap, a autora apresenta uma reflexão de conjunto, generalizante, sobre o contexto latino-americano sem, no entanto, propor a convergência dos modelos e de suas orientações. Nesse sentido, toma como ponto de partida uma definição para o termo escola de governo.

Assumimos como "escolas de governo" neste texto, para fins de análise, aquelas instituições destinadas ao desenvolvimento de funcionários públicos incluídas no aparato estatal central (nacional ou federal) ou fortemente financiadas por recursos orçamentários (INAP do México, por exemplo). Isto porque sua inserção no aparelho estatal tem fortes implicações para o debate em torno de sua missão, finalidades e desafios (PACHECO, 2000, p. 36). 
Com base nessa definição, a autora apresenta a trajetória da Enap brasileira e uma análise comparada com foco numa periodização após os anos 1980. Discute ainda o paradigma ENA e a inconsistência da tese sobre a análise das escolas em termos continentais. A seu ver, emerge um agrupamento de tipos de escola de acordo com a orientação assumida pela escolha de temas centrais.

No segundo texto, Pacheco (2002) aborda o papel das escolas de governo como centros de excelência em gestão pública. A autora esclarece que, originalmente, o foco dessas escolas era a formação da elite burocrática, mas que, com o tempo, o novo desafio passou a ser a capacitação dos quadros existentes, prioritariamente dirigentes e gerenciais, e a formação de novos profissionais para o setor público. A fim de exercer esse novo papel, a escola de governo necessita, segundo a autora, assumir o status de "escola corporativa de gestão de governo", o que implica, como nas empresas privadas, um estreito alinhamento às políticas e diretrizes do governo para a melhoria da gestão pública.

A autora argumenta que, em relação à formação continuada dos servidores, cabe ao governo decidir, em nível estratégico, sua própria agenda de prioridades para garantir a melhoria da gestão pública. Para além da transmissão dessas prioridades, uma escola corporativa de gestão do setor público deve se converter em radar das melhores práticas de gestão, exercer o papel de filtro em relação às perspectivas de aplicação em diferentes contextos e, ainda, de raio-x, no intuito de conhecer em profundidade o real funcionamento da administração pública. Ademais, faz-se necessário avaliar os impactos das ações realizadas, ou seja, fazer funcionar um sensor sobre as mudanças e resultados desencadeados pelas ações de capacitação. Finalmente, esclarece que as escolas de governo devem funcionar como learning leaders com vistas ao desenvolvimento de learning organisations, já que devem aprender cotidianamente aquilo que mais almejam ensinar: a aprendizagem permanente.

As escolas de governo foram contempladas como objeto de reflexão em dois números da revista, especificamente na seção Estudos e Pesquisas, no ano de 1994. Em ambos os textos, a autoria é institucional, sendo o primeiro da Enap, e o segundo, do Instituto Paranaense de Desenvolvimento (Ipardes). Em linhas gerais, os textos apresentam a finalidade e as perspectivas de atuação relacionadas à capacitação. Em relação às duas reportagens sobre escolas de governo, a primeira, atinente às escolas de governo europeias, foi publicada em 2006, e a segunda, sobre o encontro realizado pela Enap para o debate sobre capacitação dos servidores públicos, data de 2012. Finalmente, vale destacar a palestra realizada por Chemla (2005) sobre a reforma da École Nationale d'Administration (ENA), na França. 


\section{Educação a distância (EAD)}

Além da questão da profissionalização e das escolas de governo, outra temática destacada nos textos relacionados à formação continuada dos servidores públicos diz respeito à educação a distância. Em certo sentido, os textos que versam sobre EAD articulam as reflexões de caráter teórico sobre profissionalização com aquelas relacionadas às escolas de governo no que diz respeito à formação continuada.

Mas, afinal, o que vem a ser educação a distância?

Pesquisadores e especialistas na área propõem um sem número de propostas de conceituação, de modo que não existe uma resposta única para tal questão. Entre inúmeras possibilidades, apresentamos algumas propostas que sintetizam um certo consenso a respeito do que se entende, atualmente, por EAD. O Decreto $n^{\circ} 5.622$, de 2005, que deu nova regulamentação ao art. 80, da Lei n 9.394 , de 1996, define educação a distância como a "modalidade educacional na qual a mediação didáticopedagógica nos processos de ensino e aprendizagem ocorre com a utilização de meios e tecnologias de informação e comunicação, com estudantes e professores desenvolvendo atividades educativas em lugares ou tempos diversos". Para Moore (1996), EAD é o

aprendizado planejado que ocorre normalmente em um lugar diferente do local do ensino, exigindo técnicas especiais de criação do curso e de instrução, comunicação por meio de várias tecnologias e disposições organizacionais e administrativas especiais. (MOORE, 1996, p.2).

Segundo Preti (2009), as principais características da EAD são as seguintes:

- educando e educadores estão separados pelo tempo e/ou espaço;

- há um canal, ou melhor, canais que viabilizam a interação (canais humanos) e/ou a interatividade (canais tecnológicos) entre educadores e educandos. Trata-se, portanto, de processo mediado e "mediatizado", construindo outros sentidos aos conceitos de tempo, espaço, presencialidade e distância;

- há uma estrutura organizacional complexa a serviço do educando: um sistema de $\mathrm{EaD}$ como rede integrando comunicação, orientação acadêmica (tutoria), produção de material didático, gestão, avaliação, etc.;

- a aprendizagem é processo de construção, que se dá de forma independente, individualizada, autônoma e, ao mesmo tempo, de forma coletiva, por meio de interações sociais (com os colegas do curso, os orientadores acadêmicos, os professores, os autores do material didático) (PRETI, 2009, p. 45). 
Por constituir-se numa das principais estratégias atinentes à formação continuada, a EAD é objeto das reflexões apresentadas em 6 artigos e 1 reportagem, sendo o primeiro publicado no ano de 2007. Apesar disso, é mister destacar que Pacheco (2002) já havia inaugurado a discussão sobre o tema, ao apontar para os mitos e riscos do e-learning e, do mesmo modo, Soifer (2007), em 1971, discorria sobre o potencial da tecnologia para a promoção de uma "revolução educacional".

Com base na proposta de Minayo $(2007)^{6}$, realizamos uma análise temática de conteúdo ${ }^{7}$, cujo corpus é constituído por esses 7 textos publicados na RSP no período entre os anos de 1989 e 2016. Faremos, a seguir, a apresentação dos resultados por meio de uma abordagem quanti-qualitativa, primeiramente com uma sumária explanação sobre os dados quantitativos e, na sequência, uma breve descrição de cada um dos textos analisados. Em linhas gerais, a análise nos permitiu evidenciar algumas categorias fundamentais no teor dos artigos, a saber: relevância, desenvolvimento, sujeitos, cursos e aprendizagem.

A categoria relevância inclui as razões que justificam a importância da EAD na contemporaneidade e, fundamentalmente, suas contribuições para o processo de formação continuada dos servidores públicos. Ela inclui termos-chave tais como: democratização, inclusão, ampliação, expansão e redução de custos(economicidade). As ideias relacionadas à democratização e à inclusão pela via digital aparecem em três textos, sendo que a ampliação/expansão das possibilidades educativas por meio da EAD é um aspecto que merece atenção, já que há 36 incidências para os referidos termos no total de 4 textos. A redução de custos foi apontada como uma das vantagens da referida modalidade em 5 textos, num total de 7 vezes, mas sem representar o motivo principal para as iniciativas dessa natureza.

Em relação ao desenvolvimento, os textos evidenciam a importância da EAD como modalidade capaz de contribuir para o empowerment profissional. Os termos-chave encontrados foram os seguintes: conhecimentos (117), informações (73), competências (25), habilidades (12) e valores (4), além de menções específicas à transformação/mudança (24) decorrente do uso das tecnologias digitais de informação e comunicação para fins educacionais. Salvo melhor juízo, ainda que o conceito de competência ${ }^{8}$, do ponto de vista pedagógico, faça referência à

\footnotetext{
${ }^{6}$ A autora propõe as seguintes etapas para a análise temática de conteúdo: pré-análise, exploração do material e síntese interpretativa.

7 Os resultados obtidos podem ser tomados como aproximações em relação às categorias contempladas nos textos, uma vez que conclusões mais precisas demandariam uma análise exaustiva dos textos, tarefa que extrapola o escopo deste artigo. Obviamente, trata-se de uma entre muitas possibilidades de categorização, já que aspectos subjetivos estão envolvidos no processo de interpretação e atribuição de sentido aos dados analisados.

${ }^{8}$ Os mneumônicos "chá" e "chave" indicam a articulação entre conhecimentos, habilidades, atitudes, valores e experiências no processo de resolução de problemas.
} 
superação do modelo tradicional de educação baseado na transmissão, nos textos analisados há prevalência dos conteúdos sobre as demais dimensões, já que o conhecer assume papel de destaque no teor das discussões.

No tocante aos sujeitos, os autores se valem dos seguintes termos-chave: profissionais, servidores e público-alvo. Ademais, vale destacar que há significativa recorrência à ideia de responsabilidade individual traduzida nas palavras autoria, autonomia, autoavaliação, auto-organização, autocontrole, automonitoramento, entre outras. Há pelo menos 50 alusões a tais ideias, o que nos autoriza a afirmar que o discurso sobre EAD, no conjunto dos textos analisados, apesar de valorizar a colaboração e a interatividade, destaca a responsabilidade do sujeito pelo seu próprio processo de aprendizagem e de formação continuada sem a devida ênfase nas interfaces social e institucional que propiciam e condicionam as ações subjetivas. Pouco se discute sobre a dimensão coletiva do trabalho, e, do mesmo modo, não há indícios de uma reflexão aprofundada sobre a importância dos contextos e das condições nas quais atuam, ensinam e aprendem os profissionais do serviço público.

A análise temática revela que os cursos oferecidos na modalidade a distância são contemplados nas reflexões dos autores por meio de referências aos termos-chave qualidade, design/planejamento, conteúdos, recursos/ferramentas/ instrumentos/ materiais, ambiente virtual de aprendizagem (AVA), tutoria e autoinstrucional. São também mencionados os processos envolvidos, destacando-se a colaboração/ cooperação, interatividade, avaliação e evasão. Entre os termos mencionados, os recursos e o AVA foram contemplados em mais de 150 ocorrências, o que revela uma grande preocupação com as tecnologias utilizadas para fins educacionais. A cooperação/colaboração, o design/planejamento, os conteúdos e a avaliação tiveram quase o mesmo número de indicações, em média 30. A qualidade dos cursos, bem como suas limitações, apesar de terem sido citadas algumas vezes, não foram contempladas em todos os textos. No que diz respeito à tutoria e aos autoinstrucionais, tiveram praticamente a mesma quantidade de ocorrências, por volta de $12 / 13$, de modo que ambas as possibilidades foram contempladas e consideradas válidas para os cursos oferecidos na modalidade a distância.

Finalmente, no que diz respeito às concepções e aos processos de aprendizagem on-line, podem ser elencados alguns termos-chave tais como: tecnologia, pedagogia, metodologia e interatividade. Os dados dessa categoria tendem a confirmar o foco nas tecnologias anunciado anteriormente na categoria cursos, uma vez que foram feitas por volta de 67 alusões às TDIC e 12 às metodologias. Sobre pedagogia, foram identificadas 14 referências, sendo que 10 estavam num único texto, o que parece revelar o caráter secundário das teorias pedagógicas na fundamentação dos artigos apresentados. 
Feita a apresentação sumária dos dados quantitativos, passaremos a uma breve descrição dos textos selecionados para análise. Em 2007, foram publicados dois textos sobre EAD, sendo um artigo e uma reportagem. Abbad (2007) apresenta o processo de disseminação da modalidade a distância em moldes planetários e sua vinculação com os princípios da aprendizagem aberta e da educação permanente. Há quase dez anos, a autora destacava o papel da EAD como tendência irreversível, ao apontar para os programas de qualificação e formação profissional, a educação corporativa e as escolas de governo. O artigo apresenta uma forte ênfase nas ideias de democratização/inclusão e ampliação/expansão da educação pela via tecnológica, assim como uma reflexão que abrange uma variedade de assuntos, de modo que se constitui no texto com maior quantidade e variedade de termos-chave.

Um aspecto que merece especial destaque diz respeito à referência feita ao livro Educação a distância em organizações públicas: mesa redonda de pesquisa-ação (ChAVES FILHO, 2006), produto de um ciclo de debates promovido pela Enap. Essa obra foi elaborada com base nos dados coletados por ocasião da mesa-redonda no intuito de descrever as tendências e perspectivas da EAD em diferentes organizações públicas e privadas. Para além dos cursos on-line, a autora destaca a importância do trabalho pioneiro dessa escola de governo no debate sobre o papel da EAD no Brasil $^{9}$. São apresentados como desafios as questões metodológicas, a superação da evasão, o desenvolvimento de atitudes favoráveis de aceitação à diversidade humana e o domínio de línguas estrangeiras como condição para o diálogo entre profissionais localizados em diferentes lugares do mundo.

A reportagem de Hori (2007) constitui-se numa síntese das ideias debatidas nas palestras do Seminário Internacional de Educação a Distância, promovido pela Enap, assim como nas entrevistas concedidas por diversos participantes. Dentre os principais assuntos, destacam-se a importância do conhecimento sobre o públicoalvo dos cursos, como tornar os cursos mais atrativos e criativos, avaliação, papel do tutor e preconceitos a serem superados. Merece também destaque a breve apresentação da trajetória da Enap na área, destacando-se o início dos cursos a distância, em 1980, com a mídia impressa e, em 2004, a criação da CoordenaçãoGeral de EAD e da Escola Virtual. Segundo a autora, "entre os objetivos da EAD na Enap, encontram-se a democratização do acesso ao conhecimento, o autodesenvolvimento do servidor, o desenvolvimento de competências institucionais e a otimização de custos" (HoRı, 2007, p. 375).

Assim como o primeiro texto, a reportagem também advoga que a EAD é uma via promissora para a democratização e a inclusão. Vale ressaltar que o texto da

\footnotetext{
${ }_{9}^{9}$ Àquela época, com exceção do Exército Brasileiro e da Esaf, as demais organizações participantes do evento estavam ainda em fase de institucionalização da EAD.
} 
reportagem é o que enfatiza, com maior vigor, o conhecimento do público-alvo como condição fundamental para a concepção dos cursos oferecidos na modalidade a distância e o papel fundamental do projeto pedagógico para nortear as conexões entre tecnologia e pedagogia. Digno de nota é o fato de ser, ainda, esse texto o único a apontar para a importância do investimento na formação crítica dos servidores públicos.

Quando o ideal perseguido atualmente é um modelo de gestão de pessoas baseado em suas competências, considerar apenas o conhecimento e não incluir as habilidades e atitudes a serem desenvolvidas pelo aluno, no caso, o servidor público, não é suficiente (HORI, 2007, p. 378).

A questão da evasão nos cursos oferecidos na modalidade a distância foi amplamente discutida por Nascimento e Esper (2009). Por reconhecerem a escassez de referências sobre o assunto, especificamente no contexto das escolas de governo, as autoras apresentaram os resultados de uma pesquisa ${ }^{10}$ descritiva fundamentada numa metodologia quantitativa a partir das respostas apresentadas a um questionário eletrônico. $O$ estudo conclui que os principais fatores determinantes para a evasão no contexto definido para análise são os seguintes: acúmulo de atividades de trabalho; questões relacionadas à saúde e aos compromissos familiares; ausência de tempo de dedicação; e falta de conhecimento dos alunos sobre o esforço requerido para o cumprimento satisfatório das atividades.

Apesar da preocupação legítima em relação ao problema da evasão, no que diz respeito à reflexão sobre as categorias (dificuldades pessoais, características do curso, dificuldades profissionais e dificuldades tecnológicas), entendemos que os processos relacionados à aprendizagem deveriam ser mais explorados. No que diz respeito aos termos-chave encontrados nesse texto, especificamente na categoria aprendizagem, somente as palavras tecnologias e interatividade foram contempladas na reflexão, sem nenhuma menção à metodologia ou à pedagogia. Tal abordagem exclui um fator considerado importante nos estudos sobre evasão na $E A D$, que diz respeito à importância da mediação pedagógica on-line (PALLOFF; PRATT, 2004).

Fonseca (2011) é o único autor estrangeiro a contribuir com artigo sobre EAD e, ademais, apresenta uma proposta diferenciada, já que trata da implementação de uma solução tecnológica. Seu trabalho versa sobre a primeira experiência de um curso aberto oferecido na língua espanhola, realizado na Colômbia, e de seus desdobramentos posteriores. O pesquisador apresenta inicialmente os

\footnotetext{
${ }^{10} \mathrm{~A}$ análise sobre os fatores que contribuem para a evasão focaliza os cursos oferecidos entre outubro de 2004 e dezembro de 2007 pela Coordenação-Geral de Educação a Distância da Enap.
} 
antecedentes da iniciativa, relacionados ao tema dos recursos educativos abertos (OER, em inglês). Na sequência, destaca o caráter inovador dos cursos online abertos e massivos, os MOOC (Massive Online Open Course), especialmente a primeira experiência organizada por Stephen Downes e George Siemens sobre conectivismo e conhecimento conectivo (CCK, em inglês).

Do ponto de vista da aprendizagem, a solução tecnológica implementada pelo autor fundamenta-se na proposta de Downes (2009) sobre as condições necessárias à formação de uma rede conectiva, a saber: autonomia, interação, diversidade e abertura (AIDA). Nas conclusões, fica evidente que a limitação mais importante da proposta é, ao mesmo tempo, uma de suas maiores vantagens: a dependência de serviços online cuja provisão depende de terceiros, já que qualquer alteração ou suspensão pode comprometer todo o trabalho em andamento.

A experiência evidencia a importância dos Learning Management Systems (LMS), uma vez que facilitam o trabalho de registro, organização e gestão da informação. Ainda assim, serve como demonstração da forma pela qual a tecnologia pode ser articulada para facilitar a construção de um ambiente de informação distribuído e desestruturado em que cada cursista possa vir a ter um nível maior de controle sobre sua própria formação e condições de desenvolver a gestão pessoal da mesma. Vale ainda destacar que, apesar do foco na tecnologia, o autor foi um dos poucos a fazer referência à pedagogia.

O artigo de Filatro e Mota (2013), em contraponto ao anterior, trata justamente dos ambientes virtuais de aprendizagem. As autoras apresentam uma análise consistente sobre diferentes tipos de soluções tecnológicas relacionadas à gestão da aprendizagem e do conhecimento, bem como suas implicações. O texto é resultante das reflexões de caráter interdisciplinar desenvolvidas pelo Grupo de Trabalho Ambientes Virtuais de Aprendizagem (GT-AVA), na Enap.

A evolução dos sistemas para aprendizagem em meio eletrônico - de LMS focados na gestão de ferramentas para LCMS focados na gestão de conteúdos; para LAMS focados na gestão de atividades de aprendizagem; e, por fim, para os PLE focados na personalização dos ambientes de aprendizagem - reforça a compreensão de que a educação - mesmo aquela totalmente mediada por tecnologias, como é o caso da educação mediada por tecnologias totalmente a distância - implica ação individual e interação entre pessoas. Isso equivale a dizer que apenas ferramentas - ou apenas conteúdos - não traduzem a complexidade dos processos de ensino-aprendizagem; portanto, qualquer solução tecnológica adotada por uma instituição não pode se limitar à aquisição de produtos [...] (FILATRO; MotA, 2013, p. 116).

O texto também revela grande ênfase nas ideias de ampliação e expansão da educação pela via tecnológica. O texto, apesar de focalizar a temática dos 
ambientes virtuais de aprendizagem, contempla diversos assuntos, destacandose o design/planejamento, os recursos e os conteúdos. Com 10 referências à pedagogia, são apresentadas novas tendências que apontam para a importância da contextualização nos processos educativos, entre elas o socioconstrutivismo e a abordagem situada e a andragogia, além de novos conceitos como a heutagogia e o conectivismo.

Outro artigo publicado no mesmo ano, o de Tavares-Silva, Dias e Valente (2013), apresenta os suportes que ampararam as comunidades virtuais de aprendizagem (CVA) da Escola de Governo e Administração Pública (Egap) e da Fundação do Desenvolvimento Administrativo (Fundap) ${ }^{11}$ entre os anos de 2000 a 2012. De acordo com os autores, desde 2000 essa escola tem se dedicado ao estudo da utilização das tecnologias da informação e comunicação para fins educacionais, com especial destaque para a EAD. Nesse sentido, a finalidade é promover uma participação ativa dos cursistas no processo de aprendizagem por meio da valorização do papel central da comunicação interpessoal na dinâmica dos processos educativos.

Em síntese, os quatro suportes utilizados para o desenvolvimento da CVA são os seguintes: abordagem broadcast (dada a necessidade de atender 3.000 cursistas); mediação técnica e pedagógica, à luz da ideia do "estar-junto virtual"; participantes (alunos) responsáveis e envolvidos; e aprendizagem continuada. Trata-se de uma pedagogia fundamentada na partilha, na exposição das perspectivas pessoais e na iniciativa coletiva direcionada à inovação e à criação, razão pela qual a CVA constitui-se numa ferramenta poderosa para a discussão de ideias e construção do conhecimento (TAVARES-SILVA; DiAS; VALENTE, 2013).

Com base em suas experiências como formadores, esses pesquisadores destacam que essas comunidades estão fundamentadas no sentido de pertencimento; sobrevivem se houver foco (o que para os adultos significa valor imediato do que é aprendido); requerem identificação na prática (reciprocidade na colaboração e no trabalho contínuo); e dependem dos mediadores técnicos e pedagógicos enquanto profissionais que criam circunstâncias propícias para um trabalho efetivo com a informação com vistas à geração do conhecimento.

Finalmente, no ano seguinte, foi publicado o último artigo sobre EAD. Mathias ${ }^{12}$ e Lacerda Santos (2014) também discutem a importância das comunidades virtuais no âmbito da educação corporativa por meio da apresentação de um estudo de

\footnotetext{
${ }^{11}$ Vinculada à Secretaria da Gestão Pública do Estado de São Paulo.

${ }^{12}$ Merece destaque o fato de ser o texto uma síntese da tese de um servidor do TCU. Esse detalhe revela que a EAD já tem sido tratada como objeto de pesquisa acadêmica por parte daqueles que atuam na administração pública, iniciativa que propicia o diálogo com a comunidade acadêmica e o próprio aperfeiçoamento das atividades profissionais.
} 
caso sobre o Tribunal de Contas da União (TCU). Os autores destacam que as comunidades virtuais de aprendizagem não são uma regra no âmbito das escolas de governo, razão pela qual tal iniciativa representaria uma inovação.

Ao estimular a criação de comunidades virtuais, o TCU inova ao adotar mecanismos típicos de uma abordagem sociointeracionista, utilizando as TDICEs ${ }^{13}$ como recursos de aprendizagem.

[...] É nessa perspectiva que se criam as redes de cooperação entre indivíduos, que permitem a construção coletiva do conhecimento, base dos processos de aprendizagem das comunidades virtuais do tribunal. Trata-se de uma abordagem normalmente identificada em ambientes de educação formal e que consiste em um movimento inovador quando se trata de situações de educação corporativa, como a abordada neste texto (MATHIAS; SANTOS, 2014, p. 330).

No intuito de promover a criação de comunidades virtuais, o tribunal estimula a utilização de diversos recursos, destacando-se os fóruns de discussão. Devido à qualidade das discussões promovidas pelos participantes, os conteúdos publicados podem ser utilizados para melhorar os cursos existentes e ainda inspirar a abertura de novos cursos. Apesar de parecerem meros instrumentos de trabalho, as comunidades passaram a ser percebidas como instrumentos de aprendizagem e, portanto, a representar uma verdadeira evolução na perspectiva pedagógica que fundamenta a educação corporativa no âmbito do TCU. Vale ainda destacar a referência feita à experiência realizada no Serviço Federal de Processamento de Dados (Serpro), onde as comunidades virtuais têm sido exploradas com sucesso.

Entre os desafios relacionados à iniciativa, o conflito geracional merece especial atenção. Tomando como base a reflexão de Prensky (2001), os autores asseveram que os denominados "imigrantes digitais" apresentam resistência em relação ao uso da internet para fins de aprendizagem no contexto corporativo. As relações de poder são apresentadas pelos pesquisadores como um fator relevante, já que o compartilhamento de conhecimento é muitas vezes dificultado por aqueles que o detêm.

No caso específico das comunidades virtuais, Mathias e Santos ressaltam que as TDICEs podem tanto "subverter as antigas estruturas organizacionais quanto terem o seu uso restrito aos limites suportados pela cultura da organização" (MATHIAS e SANTOS, 2014, P. 331), já que nesse locus de aprendizagem os participantes tendem a assumir papéis de destaque em decorrência da visibilidade que lhes é garantida no ciberespaço. Para a maioria dos profissionais entrevistados, aprende-se melhor sozinho, apesar de reconhecerem a importância da colaboração para o processo de construção do conhecimento.

\footnotetext{
${ }^{13}$ Termo proposto pelo professor Gilberto Lacerda Santos para designar as tecnologias digitais de informação, comunicação e expressão.
} 
Assim como nos artigos anteriores, a ideia de ampliação foi também apresentada inúmeras vezes. Há referência às tecnologias como amplificadoras da interação entre pessoas, grupos, organizações e sociedades, bem como do acesso à informação e ao conhecimento. As iniciativas de EAD, segundo os autores, tornam-se frequentes por aumentarem a abrangência da educação corporativa, e a formação continuada é por eles apresentada como sendo um requisito da sociedade informacional. As TDICEs são anunciadas como elementos essenciais para a adaptação das organizações à nova realidade e como meio para instrumentalizar a mudança, mas não há indícios de uma reflexão sobre o papel dos servidores como agentes de transformação.

No conjunto dos textos que discutem a questão da EAD encontramos contribuições teóricas fecundas e práticas inovadoras. Nesse sentido, é importante ressaltar que há muitos indícios sobre o crescente processo de institucionalização da EAD no setor público para fins de formação continuada dos servidores. Diante do exposto, é mister destacar que as ideias de ampliação e expansão tão enfatizadas nos textos não são suficientes para a reflexão crítica sobre a EAD e suas implicações no processo de formação continuada dos servidores públicos. Com base nos estudos de Vygotsky (1981 a, b), Duran (2005; 2010) argumenta que, de acordo com os pressupostos da teoria histórico-cultural, a ideia de ampliação refere-se a aumento ou alargamento, sendo derivada do latim ampliare, amplus; bem como amplificar, do latim amplificare, significa aumentar ou intensificar. Em ambos os casos, as ideias estão relacionadas a mudanças quantitativas, razão pela qual Cole e Griffin (1980) esclarecem que, numa perspectiva dialética, as tecnologias não apenas intensificam ou ampliam os processos sociais e cognitivos já existentes, uma vez que são responsáveis por sua transformação qualitativa, ou seja, pelo surgimento de novos processos.

Com base nessa perspectiva, é importante esclarecer que há diferentes concepções de formação continuada implícitas ou explícitas nos textos analisados, e que a EAD deve ser compreendida como uma modalidade educacional voltada à inovação pedagógica e não apenas tecnológica. Segundo Marin (1995, 2000), as ideias atreladas à formação continuada incluem geralmente treinamento (tornar apto a realizar tarefas), aperfeiçoamento (tornar perfeito), capacitação (aplicação na prática, tornar capaz) e atualização (pôr em dia conteúdos), não raro com foco na instrumentalização. Apesar de não serem incorretas, tais ideias são incompletas diante das novas perspectivas de desenvolvimento voltadas ao desenvolvimento dos profissionais que atuam no setor público. Hori (2007, p. 378) assevera que "investir em um perfil de servidor público capaz de refletir criticamente sobre a realidade organizacional, construí-la e modificá-la parece ser o caminho das organizações modernas, que vêm encarando os desafios apresentados de forma inovadora". 
Para além da ampliação, precisamos reconhecer as perspectivas de transformação no processo de formação continuada. Em consonância com a proposta de Hargreaves (2002, p. 115), acreditamos que "uma inovação bem-sucedida implica mais do que aperfeiçoar habilidades técnicas". Ela deve, antes e sobretudo, instilar a capacidade de compreensão dos profissionais em relação às mudanças que estão enfrentando e ao seu papel como sujeitos - e não como objetos - da transformação.

\section{À guisa de conclusão}

A análise dos sumários da RSP revela a trajetória de um periódico dedicado ao debate sobre as questões atinentes à administração pública e, em especial, à formação continuada. Dos artigos revisitados aos atuais, as temáticas e problemáticas apresentadas ao longo das últimas três décadas revelam-se como expressões do pensamento crítico e criativo de profissionais e pesquisadores dispostos a transformar.

As reflexões a respeito da profissionalização, em sentido geral, bem como sobre escolas de governo e a educação a distância apontam para os novos desafios da contemporaneidade e suas implicações na administração pública. Nesse sentido, a formação continuada impõe-se como imperativo no contexto da denominada sociedade da informação, uma vez que não há mais profissionais formados, mas formando-se.

Em face do amplo espectro de necessidades que impelem as iniciativas de capacitação, novas metodologias têm sido desenvolvidas para atender, com qualidade, às demandas de aprendizagem no âmbito do serviço público. No contexto atual, a EAD constitui-se numa estratégia promissora - ainda que não seja a melhor e nem tampouco a única - capaz de fortalecer as iniciativas de formação continuada. Em tempos de cibercultura, a articulação entre a mediação pedagógica e tecnológica aponta para a emergência de novos espaços de conhecimento, destacando-se as comunidades virtuais de aprendizagem como locus de convergência da inteligência coletiva, interativa e colaborativa. Por esse motivo, para além da usual referência aos instrumentos e ferramentas, entendemos que estamos diante de novas interfaces ou ambientes que promovem a emergência de uma nova cultura de aprendizagem.

O conjunto de textos publicados na RSP sobre EAD enquanto estratégia de formação continuada no serviço público contempla inúmeras reflexões sobre limites e possibilidades dos cursos on-line para fins de profissionalização. Partindo das pesquisas já realizadas, é mister destacar que o atual cenário nacional aponta para a necessidade de novas investigações e publicações sobre o tema, destacando-se os estágios de institucionalização da EAD, as bases teóricas adotadas para a formação 
de autores e tutores, as dinâmicas colaborativas implementadas nas e entre as escolas de governo para fins de capacitação, bem como entre elas e as instituições de ensino e pesquisa no que diz respeito à definição de metodologias e à elaboração de conteúdos voltados ao desenvolvimento de competências profissionais.

A formação continuada precisa ser devidamente valorizada, dentro da função pública, como processo permanente e central de inovação. Desse modo, as ações educativas devem estar articuladas a um programa de luta pela qualidade com vistas à consolidação de uma nova cultura administrativa. Diante desse desafio, a RSP continua a desempenhar um papel de fundamental importância como referência para as reflexões e ações consentâneas com a profissionalização dos servidores públicos.

\section{Referências bibliográficas}

ABBAD, Gardênia da Silva Abbad. Educação a distância: o estado da arte e o futuro necessário. Revista do Serviço Público, Brasília, v. 58, n. 3, p. 351-374, 2007.

ASAZU, Claudia. Escolas de governo européias reformam o ensino e voltam-se à Europa. Revista do Serviço Público, Brasília, v. 57, n. 3, p. 427-437, 2006.

BACON, Kevin. Além da capacitação: desenvolvimento de líderes para o setor público. Revista do Serviço Público, Brasília, v. 50, n. 4, p. 81-89, 1999.

BERQuió, Urbano. Qual o papel de uma escola nacional de Administração? Revista do Serviço Público, Brasília, v. 63, n. 2, p. 237-241, 2012.

CASTELLS, Manuel. Sociedade em rede. A era da informação: economia, sociedade e cultura. Rio de Janeiro: Paz e Terra, 1999.

ChAVES FILHo, Hélio (Org.). Educação a distância em organizações públicas - Mesa redonda de pesquisa-ação. Brasília: Enap, 2006.

CHEMLA, Eliane. A reforma da formação para carreiras da ENA-França. Revista do Serviço Público, Brasília, v. 56, n. 2, p. 217-224, 2005.

Cole, Michael; Griffin, Peg. Cultural amplifiers reconsidered. In: OtSON, David. (Ed.) The social foundations of language and thought. New York: Norton \& Company, 1980.

DowboR, Ladislau. Repensando o conceito de formação. Revista do Serviço Público, Brasília, v. 45, n. 2, p. 155-169, 1994.

DURAN, Débora. Os impactos das tecnologias da comunicação e informação na educação: uma perspectiva vygotskyana. In: REUNIÃo DA AsSOCIAÇÃo NACIONAL DE PesquisA em Educação, 27., 2005, Caxambu. Anais... Caxambu: Anped, 2005.

. Letramento digital e desenvolvimento: das afirmações às interrogações.

São Paulo: Hucitec, 2010.

Escola nacional de Administração Pública (EnAP). Escolas de governo e profissionalização do funcionalismo. Revista do Serviço Público, Brasília, v. 45, n. 1, p. 187, 1994. 
Escolas de governo de todo o Brasil reúnem-se na Enap para debater capacitação dos servidores públicos. Revista do Serviço Público, Brasília, v. 62, n. 3 , p. 243-249, 2012.

FerRAREZI, Elisabete; TOMACHESKI, João Alberto. Mapeamento da oferta de capacitação nas escolas de governo no Brasil: gestão da informação para fortalecimento da gestão pública. Revista do Serviço Público, Brasília, v. 61, n. 3, p. 287-303, 2010.

Filatro, Andrea; MotA, Natália Teles da. Ambientes virtuais de aprendizagem: desafios de uma escola de governo. Revista do Serviço Público, Brasília, v. 64, n. 1, p. 109-122, 2013.

FONSECA, Diego Ernesto Leal. Cursos abertos on-line: um cenário para a gestão pessoal do conhecimento? Revista do Serviço Público, Brasília, v. 62, n. 3, p. 281296, 2011.

GAETANI, Francisco. Escolas de governo: limites e condicionalidades. Revista do Serviço Público, Brasília, v. 45, n. 2, p. 113-148, 1994.

GoleMBIEWSKI, Robert T. Public administration as a developing discipline. Nova lorque: Becker, 1977.

HARgReAves, Andy. Aprendendo a mudar: o ensino para além dos conteúdos e da padronização. Porto Alegre: Artmed, 2002.

HoRI, Larissa Mamed Hori. Com educação a distância se vai ao longe. Revista do Serviço Público, Brasília, v. 58, n. 3, p. 375-380, 2007.

IMBERnón, F. Formação continuada de professores. Porto Alegre: Artmed, 2010a.

Formação docente e profissional: formar-se para a mudança e a incerteza. 8. ed. São Paulo: Cortez, 2010b.

instituto Paranaense de Desenvolvimento (IPARDes). Projeto Escola de Governo: programa de capacitação de recursos humanos para o planejamento e a gestão governamental. Revista do Serviço Público, Brasília, v. 45, n. 2, p. 235-236, 1994.

KEINERT, Tania Margarete Mezzomo; VAZ, José Carlos. Histórico da RSP. A Revista do Serviço Público no pensamento administrativo brasileiro (1937-1989). Revista do Serviço Público, Brasília, ano 45, v. 118, n. 1, p. 9-41, $1994 a$.

A história da Revista do Serviço Público a partir da análise dos seus editoriais. Revista do Serviço Público, Brasília, ano 45, v. 118, n. 2, p. 9-34, 1994b.

KUMAR, Krishan. Da sociedade pós-industrial à pós-moderna. Novas teorias sobre o mundo contemporâneo. Rio de Janeiro: Jorge Zahar Editor, 2006.

LOJKINE, Jean. A revolução informacional. 2. ed. São Paulo: Cortez, 1999.

MAgALhÃEs, Celso de. (1942). O aperfeiçoamento dos servidores do Estado. Revista do Serviço Público, Brasília, v. 62, n. 4, p. 467-471, 2011.

MATHIAS, Emmily Flügel; SANTOS, Gilberto Lacerda. As comunidades virtuais como instrumento de educação corporativa: estudo de caso no Tribunal de Contas da União. Revista do Serviço Público, Brasília, v. 65, n. 3, p. 321-334, 2014.

MARIN, Alda Junqueira (Org.). Educação continuada: reflexões e alternativas. Campinas: Papirus, 2000. 
Educação continuada: introdução a uma análise de termos e concepções. Cadernos Cedes, Campinas, n. 36, p. 13-20, 1995.

MATtelart, Armand. História da sociedade da informação. São Paulo: Loyola, 2002. MEISTER, Jeanne C. Educação corporativa: a gestão do capital intelectual através das universidades corporativas. São Paulo: Pearson Makron Books, 1999.

MınAYo, M.C.S. O desafio do conhecimento: pesquisa qualitativa em saúde. 10. ed. São Paulo: Hucitec, 2007. 406 p.

Moore, Michael Moore; KEARSLEY, Greg. Educação a Distância-uma visão integrada. São Paulo: Cengage Learning, 2008.

NASCIMENTO, Tarcilena Polisseni Cotta; ESPER, Aniely. Evasão em cursos de educação continuada a distância: um estudo na Escola Nacional de Administração Pública. Revista do Serviço Público, Brasília, v. 60, n. 2, p. 159-173, 2009.

NeWCOMER, Kathyryn E. A preparação dos gerentes públicos para o século XXI. Revista do Serviço Público, Brasília, v. 50, n. 2, p. 5-18, 1999.

PACHECO, Regina Silvia. Escolas de governo: tendências e desafios - Enap - Brasil em perspectiva comparada. Revista do Serviço Público, Brasília, v. 51, n. 2, p. 35-53, 2000.

Escolas de governo como centros de excelência em gestão pública: a perspectiva da Enap - Brasil. Revista do Serviço Público, Brasília, v. 53, n. 1, p. 75-88, 2002.

PALlofF, Rena M.; PratT, Keith. O aluno virtual: um guia para trabalhar com estudantes on-line. Porto Alegre: Artmed, 2004.

PRENSKY, Marc. Digital natives, digital immigrants. On the Horizon, MCB University Press, v. 9, n. 5, p. 1- 6, out. 2001.

PRETI, Oresti. Educação a distância: fundamentos e políticas. Cuiabá: UFMT, 2009.

RICUPERo, Rubens. Profissionalização do servidor público: requisito para o desenvolvimento. Revista do Serviço Público, Brasília, v. 45, n. 2, p. 149-153, 1994.

RosA, Joaquim Coelho. Cidadania e civilização tecnológica: a mudança de quadros conceptuais em formação e educação. Revista do Serviço Público, Brasília, v. 56, n. 3, p. 321-329, 2005.

SAntos, Maria Helena de Castro; BRITo, Marcelo. Escolas de governo e profissionalização do funcionalismo público. Revista do Serviço Público, Brasília, v. 46, n. 1, p. 69-99, 1995.

SiqueIRA, Belmiro. (1950). Seleção e treinamento. Revista do Serviço Público, Brasília, v. 61, n. 4, p. 405-409, 2010.

SMITH, Gordon S. Novos desafios para a capacitação de liderança de alto nível na gestão e governança em um mundo globalizante. Revista do Serviço Público, Brasília, v. 54, n. 2, p. 99-117, 2003.

SoIfER, Jack. (1971). O Brasil e a revolução educacional. Revista do Serviço Público, Brasília, v. 58, n. 3, p. 381-386, 2007. 
Tavares-Silva, Tania; DiAs, Paulo; Valente, José Armando. Os suportes de uma comunidade virtual de aprendizagem: uma experiência do Governo do Estado de São Paulo, Brasil. Revista do Serviço Público, Brasília, v. 64, n. 2, p. 223-247, 2013.

Vygotsky, Lev S. Pensamento e Linguagem. São Paulo: Martins Fontes, 1991a. A formação social da mente. São Paulo: Martins Fontes, 1991b.

\section{Débora Duran}

Possui pós-doutorado em Ciências Militares pela Escola de Comando e Estado-Maior do Exército (ECEME) e doutorado em Educação pela Faculdade de Educação da Universidade de São Paulo (USP). Atualmente é professora e pesquisadora no Centro de Estudos de Pessoal e Forte Duque de Caxias (CEP-FDC) e Assessora Pedagógica do Centro de Educação a Distância do Exército (CEADEx). Contato: profdeboraduran@gmail.com 
RSP: conteúdos publicados entre 1989 e 2016

\begin{tabular}{|c|c|c|c|c|c|c|c|c|c|c|c|c|c|c|c|c|}
\hline Ano & Volumes & Ed & A & $E$ & D & $\mathbf{R}$ & EP & $\mathbf{P}$ & $\mathbf{R e}$ & $\mathbf{R R}$ & B & En & IR & $\mathbf{F}$ & $\mathrm{Te}$ & $\mathrm{Ta}$ \\
\hline \multirow{2}{*}{1989} & v.44 n. 1 & - & 1 & 2 & 1 & 1 & - & 1 & - & - & - & - & - & - & 6 & \multirow{2}{*}{12} \\
\hline & v.44 n. 2 & - & 5 & - & 1 & - & - & - & - & - & - & - & - & - & 6 & \\
\hline \multirow[t]{2}{*}{ 1990-3 } & suspensos & - & - & - & - & - & - & - & - & - & - & - & - & - & 0 & \multirow[t]{2}{*}{0} \\
\hline & v.45 n.1 & 1 & - & 9 & - & 3 & 4 & - & - & - & - & - & - & - & 17 & \\
\hline \multirow[t]{2}{*}{1994} & v. 45 n. 2 & 1 & - & 10 & - & 2 & 5 & - & - & - & 1 & - & - & - & 19 & \multirow[b]{2}{*}{66} \\
\hline & v. 45 n. 3 & 1 & - & 24 & - & 2 & 2 & - & - & - & - & - & 1 & - & 30 & \\
\hline \multirow{3}{*}{1995} & v.46 n. 1 & 1 & - & 8 & - & 2 & 2 & - & - & - & - & - & - & - & 13 & \multirow{2}{*}{22} \\
\hline & v. 46 n. $2-3$ & 1 & 5 & - & - & 2 & 1 & - & - & - & - & - & - & - & 9 & \\
\hline & v. 47 n.1 & - & 6 & 1 & - & 1 & - & - & - & - & - & - & - & - & 8 & \\
\hline \multirow[t]{3}{*}{1996} & v. 47 n. 2 & - & 6 & - & 1 & - & - & - & - & - & - & - & - & - & 7 & \multirow{3}{*}{20} \\
\hline & v. 47 n. 3 & - & 5 & - & - & - & - & - & - & - & - & - & - & - & 5 & \\
\hline & v. 48 n. 1 & - & 6 & - & - & - & - & - & - & - & - & - & - & - & 6 & \\
\hline \multirow[t]{3}{*}{1997} & v. 48 n. 2 & - & 6 & - & - & - & - & - & - & - & - & - & - & - & 6 & \multirow{3}{*}{19} \\
\hline & v. 48 n. 3 & - & 7 & - & - & - & - & - & - & - & - & - & - & - & 7 & \\
\hline & v. 49 n. 1 & - & 5 & - & - & - & - & - & - & - & - & - & - & - & 5 & \\
\hline \multirow{3}{*}{1998} & v.49 n. 2 & - & 5 & - & - & - & - & - & - & - & - & - & - & - & 5 & \multirow{3}{*}{21} \\
\hline & v. 49 n. 3 & - & 6 & - & - & - & - & - & - & - & - & - & - & - & 6 & \\
\hline & v. 49 n. 4 & - & 4 & 1 & - & - & - & - & - & - & - & - & - & - & 5 & \\
\hline \multirow{4}{*}{1999} & v. 50 n. 1 & - & 5 & - & - & - & - & - & - & - & - & - & - & - & 5 & \multirow{4}{*}{20} \\
\hline & v. 50 n. 2 & - & 5 & - & - & - & - & - & - & - & - & - & - & - & 5 & \\
\hline & v. 50 n. 3 & - & 5 & - & - & - & - & - & - & - & - & - & - & - & 5 & \\
\hline & v. 50 n. 4 & - & 5 & - & - & - & - & - & - & - & - & - & - & - & 5 & \\
\hline \multirow{4}{*}{2000} & v. 51 n. 1 & - & 5 & - & - & - & - & - & - & - & - & - & - & - & 5 & \multirow{4}{*}{21} \\
\hline & v. 51 n. 2 & - & 6 & - & - & - & - & - & - & - & - & - & - & - & 6 & \\
\hline & v. 51 n. 3 & - & 5 & - & - & - & - & - & - & - & - & - & - & - & 5 & \\
\hline & v. 51 n. 4 & - & 5 & - & - & - & - & - & - & - & - & - & - & - & 5 & \\
\hline \multirow{4}{*}{2001} & v. 52 n. 1 & - & 5 & - & - & - & - & - & - & - & - & - & - & - & 5 & \multirow{4}{*}{20} \\
\hline & v. 52 n. 2 & - & 5 & - & - & - & - & - & - & - & - & - & - & - & 5 & \\
\hline & v. 52 n. 3 & - & 5 & - & - & - & - & - & - & - & - & - & - & - & 5 & \\
\hline & v. 52 n. 4 & - & 5 & - & - & - & - & - & - & - & - & - & - & - & 5 & \\
\hline \multirow{4}{*}{2002} & v. 53 n. 1 & - & 5 & - & - & - & - & - & - & - & - & - & - & - & 5 & \multirow[b]{4}{*}{20} \\
\hline & v. 53 n. 2 & - & 4 & - & - & - & - & - & - & - & - & - & - & - & 4 & \\
\hline & v. 53 n. 3 & - & 5 & - & - & - & - & - & - & - & - & - & - & - & 5 & \\
\hline & v. 53 n. 4 & - & 6 & - & - & - & - & - & - & - & - & - & - & - & 6 & \\
\hline
\end{tabular}




\begin{tabular}{|c|c|c|c|c|c|c|c|c|c|c|c|c|c|c|c|c|}
\hline Ano & Volumes & Ed & A & $E$ & D & $\mathbf{R}$ & EP & $\mathbf{P}$ & $\operatorname{Re}$ & $\mathbf{R R}$ & B & En & IR & $\mathbf{F}$ & Te & $\mathrm{Ta}$ \\
\hline \multirow{4}{*}{2003} & v. 54 n. 1 & - & 5 & - & - & - & - & - & - & - & - & - & - & - & 5 & \multirow{4}{*}{18} \\
\hline & v. 54 n. 2 & - & 4 & - & - & - & - & - & - & - & - & - & - & - & 4 & \\
\hline & v. 54 n. 3 & - & 4 & - & - & - & - & - & - & - & - & - & - & - & 4 & \\
\hline & v. 54 n. 4 & - & 4 & - & - & - & - & 1 & - & - & - & - & - & - & 5 & \\
\hline \multirow{3}{*}{2004} & v. 55 n.1-2 & - & 5 & - & - & - & - & - & - & - & - & - & - & - & 5 & \multirow{3}{*}{16} \\
\hline & v. 55 n. 3 & - & 3 & 2 & - & - & - & - & - & - & - & - & - & - & 5 & \\
\hline & v. 55 n. 4 & - & 3 & 2 & - & - & - & 1 & - & - & - & - & - & - & 6 & \\
\hline \multirow{4}{*}{2005} & v. 56 n. 1 & - & 5 & - & - & - & - & - & 1 & 1 & - & - & - & - & 7 & \multirow{4}{*}{30} \\
\hline & v. 56 n. 2 & - & 5 & - & - & - & - & 1 & 1 & 1 & - & - & - & - & 8 & \\
\hline & v. 56 n. 3 & - & 3 & 2 & - & - & - & - & 1 & 1 & - & 1 & - & - & 8 & \\
\hline & v. 56 n. 4 & - & 5 & - & - & - & - & - & 1 & 1 & - & - & - & - & 7 & \\
\hline \multirow{4}{*}{2006} & v. 57 n. 1 & - & 5 & - & - & - & - & - & 1 & - & - & - & - & - & 6 & \multirow{4}{*}{26} \\
\hline & v. 57 n. 2 & - & 5 & - & - & - & - & - & 1 & 1 & - & - & - & - & 7 & \\
\hline & v. 57 n. 3 & - & 4 & - & - & - & - & - & 1 & 1 & - & - & - & - & 6 & \\
\hline & v. 57 n. 4 & - & 5 & - & - & - & - & - & 1 & 1 & - & - & - & - & 7 & \\
\hline \multirow{4}{*}{2007} & v. 58 n. 1 & - & 4 & 1 & - & - & - & - & 1 & 1 & - & - & - & - & 7 & \multirow{4}{*}{26} \\
\hline & v. 58 n. 2 & - & 5 & - & - & - & - & - & 1 & 1 & - & - & - & - & 7 & \\
\hline & v. 58 n. 3 & - & 4 & - & - & - & - & - & 1 & 1 & - & - & - & - & 6 & \\
\hline & v. 58 n. 4 & - & 4 & - & - & - & - & - & - & 1 & - & 1 & - & - & 6 & \\
\hline Ano & Volumes & Ed & A & $E$ & D & $\mathbf{R}$ & EP & $\mathbf{P}$ & $\mathbf{R e}$ & $\mathbf{R R}$ & B & En & IR & $\mathbf{F}$ & $\mathrm{Te}$ & $\mathrm{Ta}$ \\
\hline \multirow{4}{*}{2008} & v. 59 n. 1 & - & 4 & - & - & - & - & - & - & 1 & - & 1 & - & - & 6 & \multirow{4}{*}{25} \\
\hline & v. 59 n. 2 & - & 5 & - & - & - & - & - & 1 & 1 & - & - & - & - & 7 & \\
\hline & v. 59 n. 3 & - & 6 & - & - & - & - & - & 1 & - & - & - & - & - & 7 & \\
\hline & v. 59 n. 4 & - & 4 & - & - & - & - & - & - & 1 & - & - & - & - & 5 & \\
\hline \multirow{4}{*}{2009} & v. 60 n. 1 & - & 5 & - & - & - & - & - & - & 1 & - & - & - & 1 & 7 & \multirow{4}{*}{26} \\
\hline & v. 60 n. 2 & - & 5 & - & - & - & - & - & 1 & 1 & - & - & - & - & 7 & \\
\hline & v. 60 n. 3 & - & 4 & - & - & - & - & - & 1 & 1 & - & - & - & - & 6 & \\
\hline & v. 60 n. 4 & - & 4 & - & - & - & - & - & 1 & 1 & - & - & - & - & 6 & \\
\hline \multirow{4}{*}{2010} & v. 61 n. 1 & - & 4 & - & - & - & - & - & 1 & 1 & - & - & - & - & 6 & \multirow{4}{*}{21} \\
\hline & v. 61 n. 2 & - & 4 & - & - & - & - & - & - & - & - & - & - & - & 4 & \\
\hline & v. 61 n. 3 & - & 4 & - & - & - & - & - & 1 & 1 & - & - & - & - & 6 & \\
\hline & v. 61 n. 4 & - & 4 & - & - & - & - & - & - & 1 & - & - & - & - & 5 & \\
\hline \multirow{4}{*}{2011} & v. 62 n. 1 & - & 4 & - & - & - & - & - & - & 1 & - & - & - & - & 5 & \multirow{4}{*}{25} \\
\hline & v. 62 n. 2 & - & 5 & - & - & - & - & - & 1 & 1 & - & - & - & - & 7 & \\
\hline & v. 62 n. 3 & - & 5 & - & - & - & - & - & - & 1 & - & - & - & - & 6 & \\
\hline & v. 62 n. 4 & - & 5 & - & - & - & - & - & - & 1 & - & 1 & - & - & 7 & \\
\hline & v. 63 n. 1 & - & 5 & - & - & - & - & - & - & 1 & - & - & - & - & 6 & \\
\hline 20 & v. 63 ก. 2 & - & 5 & - & - & - & - & - & 1 & 1 & - & - & - & - & 7 & 7 \\
\hline 2012 & v. 63 n. 3 & - & 5 & - & - & - & - & - & - & 1 & - & - & - & - & 6 & 6 \\
\hline & v. 63 n. 4 & - & 6 & - & - & - & - & - & 1 & 1 & - & - & - & - & 8 & \\
\hline & v. 64 n. 1 & - & 5 & - & - & - & - & - & - & 1 & - & - & - & - & 6 & \\
\hline & v. 64 n. 2 & - & 5 & - & - & - & - & - & - & 1 & - & - & - & - & 6 & 24 \\
\hline 2013 & v. 64 n. 3 & - & 5 & - & - & - & - & - & - & 1 & - & - & - & - & 6 & 4 \\
\hline & v. 64 n. 4 & - & 5 & - & - & - & - & - & - & 1 & - & - & - & - & 6 & \\
\hline
\end{tabular}




\begin{tabular}{|c|c|c|c|c|c|c|c|c|c|c|c|c|c|c|c|c|}
\hline Ano & Volumes & Ed & A & E & D & $\mathbf{R}$ & EP & $\mathbf{P}$ & $\operatorname{Re}$ & $\mathbf{R R}$ & B & En & IR & $\mathbf{F}$ & $\mathrm{Te}$ & Ta \\
\hline \multirow{4}{*}{2014} & v. 65 n. 1 & 1 & 5 & - & - & - & - & - & - & 1 & - & - & - & - & 7 & \multirow{4}{*}{28} \\
\hline & v. 65 n. 2 & 1 & 5 & - & - & - & - & - & - & 1 & - & - & - & - & 7 & \\
\hline & v. 65 n. 3 & 1 & 5 & - & - & - & - & - & - & 1 & - & - & - & - & 7 & \\
\hline & v. 65 n. 4 & 1 & 5 & - & - & - & - & - & - & 1 & - & - & - & - & 7 & \\
\hline \multirow{5}{*}{2015} & v. 66 n. 1 & 1 & 6 & - & - & - & - & - & - & 1 & - & - & - & - & 8 & \multirow{5}{*}{35} \\
\hline & v. 66 n. 2 & 1 & 5 & - & - & - & - & - & - & 1 & - & - & - & - & 7 & \\
\hline & v. 66 n. 3 & 1 & 5 & - & - & - & - & - & - & 1 & - & - & - & - & 7 & \\
\hline & v. 66 esp & 1 & 5 & - & - & - & - & - & - & - & - & - & - & - & 6 & \\
\hline & v. 66 n. 4 & 1 & 6 & - & - & - & - & - & - & - & - & - & - & - & 7 & \\
\hline 2016 & v. 67 n. 1 & 1 & 5 & - & - & - & - & - & - & 1 & - & - & - & - & 7 & 7 \\
\hline Total & 86 edições & 15 & 375 & 62 & 3 & 13 & 14 & 4 & 21 & 41 & 1 & 4 & 1 & 1 & 575 & \\
\hline
\end{tabular}

Fonte: Elaboração própria com base na análise dos títulos publicados na RSP (1989-2016).

\section{Legenda}

$\begin{array}{llll}\text { A-Artigos } & \text { Ed-Editoriais } & \text { I - Índices remissivos } & \text { RR - RSP Revisitada } \\ \text { B-Bibliografias } & \text { En-Entrevistas } & P \text { - Palestras } & \text { Te - Total por edição } \\ \text { D-Documentos } & \text { EP-Ensino e Pesquisa } & \text { R-Resenhas } & \text { Ta - Total anual } \\ \text { E-Ensaios } & & \text { Rep - Reportagens } & \end{array}$


